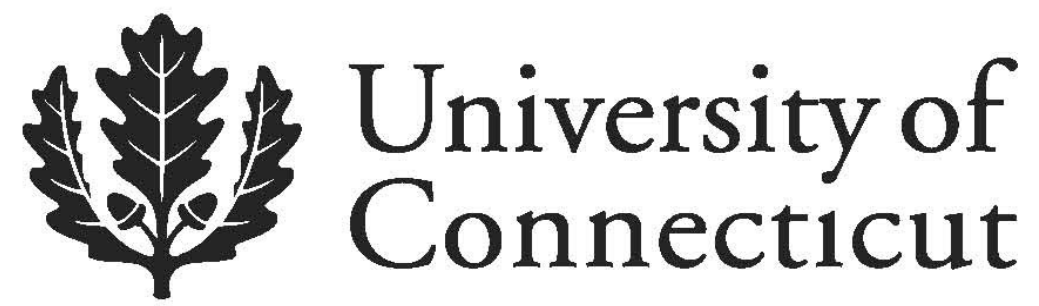

Department of Economics Working Paper Series

The effect of ESCOs on carbon dioxide emissions

WenShwo Fang

Feng Chia University

Stephen M. Miller

University of Nevada, Las Vegas

University of Connecticut

Working Paper 2012-14

August 2012

341 Mansfield Road, Unit 1063

Storrs, CT 06269-1063

Phone: (860) 486-3022

Fax: (860) 486-4463

http://www.econ.uconn.edu/

This working paper is indexed on RePEc, http://repec.org/ 


\title{
The effect of ESCOs on carbon dioxide emissions
}

\author{
WenShwo Fang \\ Department of Economics \\ Feng Chia University \\ Stephen M. Miller ${ }^{*}$ \\ Department of Economics \\ University of Nevada, Las Vegas \\ Las Vegas, Nevada, U.S.A. 89154-6005 \\ stephen.miller@unlv.edu
}

\begin{abstract}
Proponents of energy service companies (ESCOs) argue that these firms provide a crucial instrument for delivering improved energy efficiency in public and private sectors, thus contributing to carbon dioxide $\left(\mathrm{CO}_{2}\right)$ emissions reduction around the world. Do ESCOs reduce $\mathrm{CO}_{2}$ emissions? To answer this question, we develop an estimating equation, which approximates the IPAT model, from a simple model of production. Based on the modified dynamic IPAT model, using the panel data of 129 countries over the period 1980 to 2007, we provide significant evidence to show that the ESCOs effectively reduce $\mathrm{CO}_{2}$ emissions and this effect increases over time. These findings also prove robust to the inclusion of a set of control variables, different dates of the first ESCO, and the Kyoto Protocol. Finally, we discuss energy policy implications.
\end{abstract}

Keywords: $\quad$ Energy service companies (ESCOs), Carbon dioxide $\left(\mathrm{CO}_{2}\right)$ emissions, Dynamic IPAT model

JEL Classification: Q55, Q56

* Corresponding author 


\section{Introduction}

The 1992 international environmental treaty, United Nations Framework Convention on Climate Change (UNFCCC), aimed to stabilize greenhouse gas (GHG) concentrations in the atmosphere at a level that would prevent dangerous anthropogenic interference with the climate system. The 1997 Kyoto Protocol established legal obligations for most developed countries and some central European transition economies (defined as Annex B countries) to reduce their GHG emissions, on average, to 6 to 8 percent below 1990 levels between 2008 and 2012. Investment in energy-efficiency technologies provides a key component to achieve global commitments to reduce GHG emissions and global warming (Popp, 2004, 2010; Linares and Perez-Arriaga, 2009; Linares and Labandeira, 2010; Sarkar and Singh, 2010). One mechanism to promote investment in energy-efficiency technologies and, thus, to reduce GHG emissions engages energy performance contracting (EPC) undertaken by energy service companies (ESCOs). Since the early 1970s, high energy prices, greater energy demand, climate change, global warming, emerging carbon markets, environmental concerns, and international agreements, such as the Kyoto Protocol, created opportunities for the development of ESCO business (Goldman et al., 2005; Vine, 2005; Bertoldi et al., 2006; Kiss et al., 2007; Urge-Vorsatz et al., 2007; Ellis, 2010). This paper examines the effect of ESCO activities on global carbon dioxide $\left(\mathrm{CO}_{2}\right)$ emissions, which the Intergovernmental Panel on Climate Change (IPCC, 2007) identifies as the most important anthropogenic GHGs.

An ESCO offers energy-efficiency technologies, including development and design of energy efficiency and emission reduction projects, installation and maintenance of energy efficient equipment, monitoring and verification of the project's energy savings, and finally, a guarantee of the savings for clients in the public, industrial, commercial or residential sector (Vine, 2005; WEC, 2008; Ellis, 2010). The ESCO's revenue directly links to the amount of energy saved through the 
EPC. Two main EPC models exist: the shared savings model and the guaranteed savings model (Bertoldi et al., 2006; Okay et al, 2008). In the first model, the ESCO and the client share the cost savings at a pre-determined percentage for a fixed number of years. In the guaranteed savings model, the ESCO guarantees a certain level of energy savings to the customer. Financing for the investment can either come from the internal funds of the ESCO, from the customer, or from a third-party funding source, where a financial institution allows a credit for the ESCO or directly to its client. A guarantee for the projected energy or cost savings given by the ESCO backs the loan.

ESCOs emerged in the US in the 1970s after the oil crisis, which led to increasing energy prices. They grew during the utility integrated resource planning and demand side management (DSM) era of the late 1980s and early 1990s. Now, the US possesses the most mature ESCO market in the world. Energy-efficiency technologies represent a major share of the industry activity, accounting for 75 percent of ESCO revenues in 2008 (Goldman et al., 2005; Urge-Vorsatz et al., 2007; Satchwell et al., 2010). The concept gradually spread to Europe and Japan (Vine et al., 1998; Shito, 2003; Vine, 2005; Bertoldi et al., 2006; Patlitzianas et al., 2006; Kiss et al., 2007; Patlitzianas and Psarras, 2007). For example, Italian ESCO activity began in the early 1980s (Vine, 2005), and now, ESCOs account for 90 percent of energy-efficiency activity (Linares and Perez-Arriaga, 2009). In the 1990s, the ESCOs emerged in developing countries (Davies and Chan, 2001; Lee et al., 2003; Okay et al., 2008; Ellis, 2010). By 2008, China housed the largest ESCO industry in the developing world by total investment (Taylor et al., 2008). Today, international agencies view the ESCO industry as the new business model to promote energy efficiency in the world (Bleyl, 2009; Limaye and Limaye, 2009; Singh et al., 2009; Sarkar and Singh, 2010; Ellis, 2010). Some key international agencies involved in ESCO development include the World Bank, the Asian Development Bank, and the US Agency for International Development (ESMAP, 2006; 
ADB, 2009; USAID, 2010).

Vine (2005) and Goldman et al. (2005) analyze the results of a survey on ESCO activity in 38 countries outside of the US and the US, respectively. Vine (2005, Table 7) gives details on most important barriers facing the ESCO industry in various countries such as customers and engineering companies unfamiliar with or uninterested in ESCOs and EPC, lack of financing, low energy prices, lack of government support, commitment, and leadership by example, and so on. In some countries, ESCO-industry associations; financing, measurement and verification protocols; and information and education programs are some key mechanisms for promoting ESCO projects. Moreover, countries that remove subsidies, and privatize the energy industry and the power sector will lead the development of the ESCO industry. Goldman et al. (2005) find that EPC overcomes market barriers for energy-efficiency investments among large, institutional, public-sector customers in the US. Recently, Sarkar and Singh (2010) provide ideas for scaling up energy-efficiency investments through EPCs. They propose an innovative public-private partnership business model (i.e., a Super ESCO) to bundle public facilities to lower transaction costs, bring in economies-of-scale, and attract large service providers into the markets.

Using the international survey data from Vine (2005), Okay and Akman (2010) plot relationships among a set of ESCO indicators (age of ESCO market, number of ESCO companies, total value of ESCO projects, and sectors targeted by ESCOs) and country indicators (per capita GDP, energy consumptions, $\mathrm{CO}_{2}$ emissions, and global innovation index). They find important dependences between ESCO activity indicators and country indicators such as the global innovation index. In their descriptive study, the positive slope (or correlation) of each of the ESCO indicators with respect to $\mathrm{CO}_{2}$ emissions leads the authors to conclude the ineffectiveness of ESCOs in most of the countries. 
Do ESCOs reduce $\mathrm{CO}_{2}$ emissions? To answer this question, we use an empirical approach to examine the effect of ESCOs on $\mathrm{CO}_{2}$ emissions. To the best of our knowledge, we provide the first econometric analysis of this issue. Based on the IPAT formula (Ehrlich and Holdren, 1971; 1972; Commoner et al., 1971), we derive an estimating equation from a simple production model of $\mathrm{CO}_{2}$ emissions. We estimate a dynamic panel model for a sample of 129 countries from 1980 to 2007. We provide new evidence that ESCOs effectively reduce $\mathrm{CO}_{2}$ emissions and this result proves robust to the inclusion of a set of control variables, different dates of the first ESCO, and the Kyoto Protocol. Moreover, the ESCO effect increases over time.

The rest of the article flows as follows. Section 2 presents a brief review of the dynamic IPAT model and its properties. Section 3 describes the data, reports and discusses the results. Section 4 concludes.

\section{A dynamic IPAT model}

The well-known IPAT (or I=PAT) model tries to identify the environmental impact (I) of the product of three factors: population size (P), affluence of the economy (A) measured by per capita GDP, and the existing technology $(\mathrm{T})$ measured by the environmental impact per unit of economic activity. The Kaya identity (Yamaji et al., 1991; Raupach et al., 2007) provides a specific application of the IPAT identity. It decomposes the global $\mathrm{CO}_{2}$ emissions driving forces into four multiplicative factors: global population, global GDP per capita (i.e., GDP/Population), energy intensity of world GDP (i.e., Energy/GDP), and carbon intensity of energy (i.e., $\mathrm{CO}_{2} /$ Energy). In the same form, Waggoner and Ausubel (2002) developed the ImPACT model to predict total $\mathrm{CO}_{2}$ emissions. While the ImPACT model identifies some factors that when reduced, can reduce $\mathrm{CO}_{2}$ emissions, like the IPAT and the Kaya identities, the ImPACT model also is a definition and does not emerge from some underlying theoretical model. Rather, it is an ad hoc identity that does not 
permit hypothesis testing for the underlying driving forces of environmental change. These equations, however, may help assess the effect of ESCO activity as another indicator of the technological factor on environmental degradation.

To estimate the effects of population, affluence, and technology on $\mathrm{CO}_{2}$ emissions, Dietz and Rosa $(1994,1997)$ and York et al. (2003) reformulate IPAT into a stochastic impacts by regression on population, affluence, and technology (STIRPAT) model as follows:

$$
I_{i}=a P_{i}^{b} A_{i}^{c} T_{i}^{d} e_{i},
$$

where the subscript $i$ denotes the country; a, b, c and d are parameters to be estimated; $e_{i}$ is the error term. After taking natural logarithms, the model becomes:

$$
\ln I_{i}=\ln a+b \ln P_{i}+c \ln A_{i}+d \ln T_{i}+\varepsilon_{i},
$$

where $\varepsilon_{i}=\ln e_{i}$

We now propose a simple model of $\mathrm{CO}_{2}$ that generates an estimating equation similar to that of equation (2). First, we formulate the problem as a production process for $\mathrm{CO}_{2}$ emissions. Such emissions come from the use of energy resources. We propose a simple Cobb-Douglas production function for $\mathrm{CO}_{2}$ emissions as follows:

$$
I_{i}=a_{i} E_{i}^{\alpha} e^{\varepsilon_{i}},
$$

where $\quad I=\mathrm{CO}_{2}$ emissions;

$$
\begin{aligned}
& a=\text { the technological, structural, and other effects; } \\
& E \text { = energy use; } \\
& e=\text { the Euler's number, and }
\end{aligned}
$$


$\varepsilon=$ the error term.

Demographic and economic developments play a crucial role in determining $\mathrm{CO}_{2}$ emissions.

We can augment this equation by dividing both sides of this production function for $\mathrm{CO}_{2}$ emissions

by population and then real GDP as follows:

$$
\left(\frac{I}{P}\right)_{i}=a_{i} \frac{E_{i}^{\alpha}}{P_{i}} e^{\varepsilon_{i}}=a_{i}\left(\frac{E}{P}\right)_{i}^{\alpha}\left(\frac{1}{P_{i}}\right)^{(1-\alpha)} e^{\varepsilon_{i}}=a_{i}\left(\frac{E}{Y}\right)_{i}^{\alpha}\left(\frac{Y}{P}\right)_{i}^{\alpha}\left(\frac{1}{P_{i}}\right)^{(1-\alpha)} e^{\varepsilon_{i}}
$$

where $\quad P=$ population; and

$$
Y=\text { real GDP. }
$$

Thus, taking natural logarithms gives us

$$
\begin{aligned}
& \ln \left(\frac{I}{P}\right)_{i}=\ln a_{i}-(1-\alpha) \ln P_{i}+\alpha \ln \left(\frac{Y}{P}\right)_{i}+\alpha \ln \left(\frac{E}{Y}\right)_{i}+\varepsilon_{i} \text {; or } \\
& \ln I_{i}=\ln a_{i}+\alpha \ln P_{i}+\alpha \ln \left(\frac{Y}{P}\right)_{i}+\alpha \ln \left(\frac{E}{Y}\right)_{i}+\varepsilon_{i} .
\end{aligned}
$$

Equation (6) matches equation (2), where $b=c=d=\alpha$. That is, we can characterize the literature's STIRPAT model as the simple production function (for $\mathrm{CO}_{2}$ in this case), where the restrictions on the coefficients of population, real GDP per capita, and energy use per real GDP (i.e., energy intensity) are relaxed. Note that the translation of variables from our formulation to STIRPAT is as follows:

$$
\mathrm{A}_{i}=\left(\frac{Y}{P}\right)_{i} \text { and } T_{i}=\left(\frac{E}{Y}\right)_{i}
$$

Furthermore, one can think of additional control variables that can affect $\mathrm{CO}_{2}$ emissions 
through the constant term as follows:

$$
a_{i}=a X_{i}^{g} \text { or } \ln a_{i}=\ln a+g \ln X_{i}
$$

In the additive regression (6), we express all variables in natural logarithmic form to facilitate estimation and hypothesis testing, where $a_{i}$ includes all variables other than population. real GDP per capita, and energy use per real GDP. Researchers use the STIRPAT model to analyze the effects of different driving forces on a variety of environmental effects (Shi, 2003; York et al., 2003; Cole and Neumayer, 2004; Martinez-Zarzoso et al., 2007; Grunewald and Martinez-Zarzoso, 2009; Iwata and Okada, 2010; Poumanyvong and Kaneko, 2010; Martinez-Zarzoso and Maruotti, 2011). For example, Shi (2003) argues that the difference in energy intensity, which is $\mathrm{T}$ in the IPAT equation, could depend on the differences in economic structures between countries. Countries whose GDP depends heavily on manufacturing will use more energy and will produce higher $\mathrm{CO}_{2}$ emissions; whereas countries whose GDP depends largely on services will use less energy and will produce lower emissions. Shi (2003), thus, specifies two variables: the share of the industry and service sectors in GDP in the STIRPAT model to examine the effect of population on global $\mathrm{CO}_{2}$ emissions. Poumanyvong and Kaneko (2010) employ the STIRPAT model and add urbanization as an additional variable to investigate its impact on $\mathrm{CO}_{2}$ emissions.

The IPAT model views population coupled with growing affluence as the primary forces driving adverse environmental effects (Dietz and Rosa, 1997; Shi, 2003; York et al., 2003; Martinez-Zarzoso et al., 2007). Another category of work, the environmental Kuznets curve (EKC), focuses on an inverted-U relationship between environmental degradation and economic growth. That is, pollutants such as $\mathrm{CO}_{2}$ emissions worsen in the early stages of growth, but eventually peak and start declining as income passes a certain threshold level (Grossman and Krueger, 1995; Dasgupta et al., 2002; Dinda, 2004; Stern, 2004; Brock and Taylor, 2010; Carson, 2010; Kijima et 
al., 2010). Empirical models, which test for the EKC hypothesis, typically regress $\mathrm{CO}_{2}$ emissions per capita on per capita GDP and a squared term of per capita GDP along with other explanatory variables. If the coefficient of the squared term proves significantly negative and the estimated extreme point falls within the data range, it concludes that an inverted-U relationship exists. The existing findings generally show that $\mathrm{CO}_{2}$ emissions increase monotonically with per capita income, start declining at income levels well beyond the observed range, or depend on different income levels and regions (Holtz-Eakin and Eslden, 1995; Cole et al., 1997; Lee et al., 2009; Caviglia-Harris et al., 2009; Gassebner et al., 2011). No unanimous evidence supports the inverted-U relationship yet.

Both population and per capita income lead to environmental pressure in either total or per capita $\mathrm{CO}_{2}$ emissions. We focus on the total measure of the pollutant because it directly links to climate change and global warming. In the IPAT framework, the technology factor critically determines environmental improvement. Technological advance must control global $\mathrm{CO}_{2}$ emissions to offset, at least partly, the adverse effect of population and per capita income growth to achieve a sound process of sustainable world development. ESCOs can contribute to the effort by developing public and private projects designed to improve energy efficiency.

Empirical implementations of the STIRPAT model employ panel data techniques to ameliorate a number of statistical problems with cross-country investigations (Shi, 2003; Cole and Neumayer, 2004; Martinez-Zarzoso et al., 2007; Iwata and Okada, 2010; Poumanyvong and Kaneko, 2010; Martinez-Zarzoso and Maruotti, 2011). To examine the effect of ESCOs on $\mathrm{CO}_{2}$ emissions, we develop a dynamic, panel-data IPAT model that explicitly captures the dynamics of adjustment in the $\mathrm{CO}_{2}$ series. The idea is straightforward. It takes time to reach any of the GHG emissions reductions targets such as the levels proposed by the Kyoto Protocol. The process of 
moving toward the target gradually implies that current and lagged $\mathrm{CO}_{2}$ emissions are correlated. This dependency suggests using a dynamic model to capture the lagged effect. And finally, adding a variable to capture ESCO activity completes our estimation equation as follows:

$$
\begin{aligned}
\ln I_{i t}=\mu_{i}+\eta_{t}+b \ln I_{i t-1} & +c \ln P_{i t}+d \ln A_{i t}+e \ln T_{i t} \\
& +f E S C O+g \ln X_{i t}+\varepsilon_{i t}
\end{aligned}
$$

where the subscript $t$ denotes the year. Note that with panel data, our constant $\ln a$ in equation (8) becomes a country-specific fixed-effect, $\mu_{i}$, along with a year-specific fixed-effect, $\eta_{t}$, and the error term, $\varepsilon_{i t}$.

In the dynamic panel-data model, $I_{i t}\left(I_{i t-1}\right)$ equals $\mathrm{CO}_{2}$ emissions in kilotons (kt) in country $i$ at year $t(t-1) . P_{i t}$ is total population. $A_{i t}$ is real per capita GDP in PPP (purchasing power parity 2005 constant international dollars). $T_{i t}$ is energy intensity defined as the amount of energy use per unit of real GDP in PPP (2005 constant international dollars). The ESCO dummy variable equals one beginning in the year the country started its ESCO business; zero otherwise. We also modify this specification and include the number of years of ESCO activities and its squared term to examine the ESCO effect over time. $X_{i t}$ is a set of control variables: per capita GDP squared to test for the EKC hypothesis (Caviglia-Harris et al., 2009, Gassebner et al., 2011), the percentage share of industry (including manufacturing) and service sectors value added in GDP to account for the effect of economic structure (Shi, 2003), the percentage of total population living in urban areas to measure the effect of urbanization (Poumanyvong and Kaneko, 2010; Martinez-Zarzoso and Maruotti, 2011), and the Kyoto dummy variable, which equals one beginning in the year of treat's adoption; zero otherwise, to evaluate the role of the Kyoto Protocol (Iwata and Okada, 2010; Almer and Winkler, 2011).

The inclusion of $\ln I_{i t-1}$ as a regressor leads to biased and inefficient OLS estimates due to 
correlation between the lagged dependent variable and the error term. Moreover, two additional econometric problems may arise from estimating equation (9): the explanatory variables are probably endogenous and the country-specific effect may correlate with the explanatory variables. To solve these problems, we use the generalized method of moments (GMM) difference estimator proposed in Arellano and Bond (1991) (see Roodman, 2009, for applications). This method takes the first differences of equation (9) to remove the country-specific fixed-effect and permits the use of lags of the levels of regressors and the dependent variable as instrumental variables, and thereby provides more precise estimates of the relationship. The regression needs to pass two standard specification tests: Sargan and serial correlation. The null hypothesis of the former states that the instruments do not correlate with the residuals from the respective regression. The null hypothesis of the latter states that the errors in the first-difference regression exhibit no second-order serial correlation (significant negative first-order serial correlation is allowed). Evidence that supports

the efficacy of ESCOs in reducing $\mathrm{CO}_{2}$ emissions emerges when the coefficient of the ESCO dummy variables proves significantly negative (i.e., $f<0$ ).

\section{Data, estimation results and discussion}

\section{Data description}

We use a panel dataset of 129 countries covering the period from 1980 to 2007. ESCOs first appeared in the late 1970s and early 1980s in a few countries such as Canada, Sweden, the UK, and the US. Most ESCO activities began in the late 1980s and 1990s, and the number of ESCO countries continued to grow in the 2000s. In equation (9), we proxy for ESCO activity with the dummy variable, which equals one the year ESCO activity began in the country; zero otherwise. In his international survey, Vine (2005) lists 38 countries (outside of the US) that became involved in ESCO activities with the initial year or range of years when that activity began. Given the ranges, 
we use the mid-point as the starting year. For example, the range for Argentina and Philippines is the 1990s, then we adopt 1995 as the time of the first ESCO, Germany’s range equals 1990 to 1995 , meaning that we adopt 1993 as the starting year, Italy's range equals the early 1980s, which we translate into 1983 as the starting year, and finally, Hungary’s range of the late 1980s to the early 1990s leads us to adopt 1990 as the starting year. In a pan-European survey of ESCOs, Kiss et al. (2007) provide some new European ESCO countries in addition to starting dates for ESCO activity that differ from those in Vine (2005) for some countries. We use these alternative dates as a robustness check on our results. Table 1 lists the ESCO countries and their starting years from Vine (2005) and Kiss et al. (2007). The US started its ESCOs in the 1970s (Urge-Vorsatz et al. 2007). To avoid confusion, we refer to the different dates as the Vine or Kiss starting years. In the model estimation, the latter is eventually composed of Kiss et al. (2007) pan-European data plus countries outside of Europe in Vine (2005) and the US. Table 1 also lists 39 countries and the years they ratified the Kyoto Protocol. ${ }^{1}$ These countries approved the quantified emission limitation or reduction commitments, which are legally binding.

The data on $\mathrm{CO}_{2}$ emissions, population, per capita GDP, energy intensity, urbanization, the share of the industry and service sectors value added in GDP come from the World Development Indicators published by the World Bank. ${ }^{2}$ The data on $\mathrm{CO}_{2}$ emissions and total energy use originally come from the Carbon Dioxide Information Analysis Center of Oak Ridge National Laboratory and the International Energy Agency (IEA), respectively. Table 2 reports a detailed description of the variables, preliminary statistics of the data, and simple correlation coefficients between the variables in the model.

The highly significant positive correlation $(=0.9989)$ between current $(I)$ and the lagged

\footnotetext{
1 Data downloaded from http://unfccc.int.

2 Data downloaded from http://data.worldbank.org/data-catalog.
} 
$\left(I_{t-1}\right) \mathrm{CO}_{2}$ suggests a dynamic model. The positive correlations between $\mathrm{CO}_{2}$ emissions and each of the other variables studied accords with priors, since all human activities increase $\mathrm{CO}_{2}$ emissions. Okay and Akman (2010), based on the positive correlations between per capita $\mathrm{CO}_{2}$ emissions and three ESCO indicators -- the age of the ESCO market, the number of ESCOs, and total value of ESCO projects -- conclude that ESCOs contributed to the more $\mathrm{CO}_{2}$ emissions. Drawing conclusions based on bivariate correlations can lead to erroneous conclusions, as we will demonstrate. We use an aggregate ESCO measure (the dummy variable) and employ an empirical approach (the dynamic IPAT model) to examine the effect of ESCOs on $\mathrm{CO}_{2}$ emissions. We have derived an estimating equation similar to the stochastic IPAT model based on a production model of $\mathrm{CO}_{2}$ emissions.

\section{Estimation results}

Table 3 reports the results from the difference GMM estimator. ${ }^{3}$ First, we estimate equation (9), where we regress $\mathrm{CO}_{2}$ emissions $\left(I_{t}\right)$ on lagged $\mathrm{CO}_{2}$ emissions $\left(I_{t-1}\right)$, population $(P)$, real per capita GDP (A), and energy intensity (T) (Model 1) with standard errors in parentheses, statistics for the Sargan and autocorrelation tests, and p-values in brackets. This baseline model incorporates only the basic elements from our theoretically derived and modified IPAT framework. The results indicate that all four explanatory variables are statistically significant at the 1-percent level and display the expected signs. The lagged dependent variable explains the largest part of current $\mathrm{CO}_{2}$ emissions, lending support to the dynamic specification. A 1-percent increase in population associates with a 0.3389-percent increment in $\mathrm{CO}_{2}$ emissions. In the log-log specification, the coefficient estimates represent elasticities or the ratios of percent changes. The $\mathrm{CO}_{2}$ - real per capita GDP elasticity equals 0.6165 , or a 1-percent increase in real per capita GDP associates with a

\footnotetext{
${ }^{3}$ We estimate the GMM results using the Stata command xtabond2 (see Roodman, 2009).
} 
0.6165 percent increase in $\mathrm{CO}_{2}$ emissions. Energy intensity exhibits an elasticity for $\mathrm{CO}_{2}$ emission of 0.5060 . Note that in our dynamic IPAT model, the estimates report short-run elasticities. The long-run elasticities take the short-run parameters and divide them by 1 minus the coefficient on the lagged $\mathrm{CO}_{2}$ variable. Thus, they are 1.2013, 2.1963 and 1.8026, respectively, for population, real per capita GDP, and energy intensity. The regression passes the standard specification tests: the two-step Sargan test for over-identification does not reject the null, and the test for first-order serial correlation rejects the null of no first-order serial correlation, but it does not reject the null of no second-order serial correlation.

Second, we estimate the dynamic IPAT model by including the dummy variable for ESCO activity in Model 2, where we still exclude the other explanatory variables. The dummy equals one from the year of the first ESCO activity, zero otherwise, based on Vine's (2005) ESCO country data in Table 1. The coefficient of the ESCO dummy proves significantly negative at the 1-percent level. All other estimates and the diagnostic statistics match those in the baseline Model 1. These results suggest that ESCOs effectively reduce $\mathrm{CO}_{2}$ emissions. York et al. (2003) interpret the coefficient of the dummy variable as follows. The negative sign indicates that $\mathrm{CO}_{2}$ emissions decrease. The antilog of the coefficient for the ESCO dummy variable shows the ratio of $\mathrm{CO}_{2}$ emissions with ESCO activity to that without such activity. For example, the antilog of the coefficient of -0.0615 equals 0.9404 , indicating that ESCO countries produce about 94 percent of the $\mathrm{CO}_{2}$ emissions of non-ESCO countries, controlling for other factors. In other words, ESCO countries exhibit approximately 6-percent lower $\mathrm{CO}_{2}$ emissions.

Recent studies also debate the existence of an effect of the Kyoto Protocol on $\mathrm{CO}_{2}$ emissions. Third, to examine this issue, Model 3 adds the dummy variable for the Protocol to Model 2. The coefficient of the KYOTO proves significantly negative at the 5-percent level, 
suggesting that the Kyoto Protocol does reduce $\mathrm{CO}_{2}$ emissions. Moreover, the coefficient for ESCO dummy variable remains negative and significant at the 1-percent level. Note that the estimate of ESCO (= -0.0678) is much higher than the estimate of KYOTO (= -0.0123). The ESCO industry provides a more effective tool than the international agreement of the Kyoto Protocol to reduce global $\mathrm{CO}_{2}$ emissions. The Kyoto Protocol reduces $\mathrm{CO}_{2}$ emissions by approximately 1.12 percent.

Fourth, we estimate equation (9) where we include all the other variables, but still use the Vine dating of ESCO adoption. Does the significant negative $\mathrm{CO}_{2}-E S C O$ relationship still hold, if we accommodate the potential linkages between squared per capita GDP, urbanization, industry share, service share, and $\mathrm{CO}_{2}$ emissions. We address this concern with Model $4{ }^{4}$ The estimates indicate that the other factors do produce significant effects on $\mathrm{CO}_{2}$ emissions, except for the population living in urban areas. Also, the KYOTO dummy variable now becomes insignificant. Adding other factors to the model does not alter in any major way the coefficients for the lagged dependent variable, population, technology, and ESCO. The positive coefficient for real per capita GDP suggests that $\mathrm{CO}_{2}$ emissions initially rise with per capita GDP, and then eventually fall, given the negative coefficient on the squared real per capita GDP term, tending to support the EKC hypothesis. The effect of the industrial sector exceeds the effect of service sector, not a surprise. The negative $\mathrm{CO}_{2}-E S C O$ relationship remains robust to the inclusion of the Kyoto Protocol and the set of other control variables.

Fifth, to further check the robustness of the effect of ESCO activities on $\mathrm{CO}_{2}$ emissions, we ask whether the finding on the negative $\mathrm{CO}_{2}-E S C O$ relationship continues to hold if we use the different dates of the first ESCO activity. That is, we use the dates from Kiss et al. (2007) for the

\footnotetext{
4 This model resembles the specification that Poumanyvong and Kaneko (2010) use in their study, except ours adopts a dynamic specification.
} 
pan-European ESCO countries data combined with the international data from outside Europe in Vine (2005), and the US date of the first ESCO activity from Urge-Vorsatz et al. (2007) to replace the Vine data used in Models 2, 3, and 4. That is, Models 5, 6, and 7 report the estimation results that correspond to Models 2, 3, and 4, except with the new pattern of dates in the Kiss data. In each of the three models, the coefficient of the ESCO dummy variable confirms a significant negative association between $\mathrm{CO}_{2}$ emissions and ESCOs at the 1-percent level. Thus, the model adjusting for different years of the first ESCO yields robust results with regard to the effect of ESCO activities on $\mathrm{CO}_{2}$ emissions.

Finally, we use the number of years since the permitting of ESCO activities (year) and its squared term $\left(\right.$ year $\left.^{2}\right)$ to examine the ESCO effect over time. ${ }^{5}$ At this stage, we take the most robust variables and estimate the final model. That is, we exclude the squared term of real GDP per capita and urbanization in the final model. Model 4 suggests a potential EKC. The estimated turning point occurs at a high level of per capita GDP $(\ln A=14.53)$, which far exceeds the income range (ln $A \in[5.49,11.47]$ ) in our sample. The negatively estimated coefficient on the squared affluence term proves insignificant in Model 7, where we only use different data set for the years of the first ESCO activity. Thus, no robust evidence supports the inverted-U relationship between $\mathrm{CO}_{2}$ emissions and real per capita GDP. Although urbanization positively influences $\mathrm{CO}_{2}$ emissions, the coefficient is insignificant in Models 4 and 7, however.

Table 4 reports the results. Models 8 and 11 re-estimate the specification with the ESCO dummy variable without the squared value of real GDP per capita and the urbanization variable. ${ }^{6}$

\footnotetext{
${ }^{5}$ Our data on ESCOs only identifies when ESCO operations initiated in each country. We do not know exactly the size of these operations and/or how these activities changed over time after the initial adoption. Thus, we interact the ESCO dummy variable, since the initial permitting of ESCO activities, to examine the ESCO effect over time.

${ }^{6}$ Models 8, 9, and 10 use the Vine (2005) dating of ESCO whereas Models 11, 12, and 13 correspond to Models 8, 9, and 10, respectively, but use the modified dates on ESCO as reported by Kiss et al. (2007).
} 
Removing these two factors does not substantively alter the size and significance of the coefficients for ESCO. Furthermore, adding other factors to the basic model (Model 1) does not dramatically change the coefficients for population, affluence and technology. The models with interaction terms fit the data well. All variables exhibit significant coefficients. To test for the null of no effect of ESCOs, we test if the estimates of ESCO and ESCO*year (ESCO, ESCO*year, and ESCO $^{*}$ year $^{2}$ ) equal zero jointly in Models 9 and 12 (10 and 13) using a $\chi^{2}$-test. The high $\chi^{2}$-statistic rejects the null, suggesting the interaction effects of ESCOs in each of the four models. We, therefore, primarily focus our discussion on the final models.

\section{Discussion}

In the theoretically derived and modified dynamic IPAT model, lagged $\mathrm{CO}_{2}$ clearly and significantly predicts current $\mathrm{CO}_{2}$ emissions. In the six final models, the significant coefficient on lagged $\mathrm{CO}_{2}$ lies consistently around 0.67 at the 1 -percent level. The models also consistently pass the two standard specification tests: no correlation between the instruments used with the residuals from the respective regression and no second-order serial correlation in the errors of the first-differenced regression, indicating that we achieve the appropriate specification of the dynamic model.

Population generally associates with higher $\mathrm{CO}_{2}$ emissions. The population elasticity of effect for $\mathrm{CO}_{2}$ emissions ( 0.3755 in Model 10 , for example) appears to fall below the estimate of 1.123 in Dietz and Rosa (1997), 1.416 in Shi (2003), 0.976 in York et al. (2003), 1.103 in Cole and Neumayer (2004), and, more recently, 1.125 in Poumanyvong and Kaneko (2010). These studies all use a static STIRPAT model with different estimators, however. Since the authors did not include the lagged dependent variable in their models, the coefficient estimates reflect long-run elasticities. In our dynamic IPAT model, the short-run estimate in Model 10 implies a long-run 
population elasticity of 1.1417 (= 0.3755/(1-0.6711)), which then matches closely to these studies. Additionally, the population estimate proves consistent with the coefficients estimated between 0.198 to 0.319 in Martinez-Zarzoso and Maruotti (2011), who do adopt a dynamic model, but with different estimators. ${ }^{7}$

The affluence coefficient exerts the most positive effect among all factors across models, meaning that growing affluence proves a major determinant of deteriorating $\mathrm{CO}_{2}$ emissions. The long-run affluence elasticity equals 1.8693 in Model 10, implying that a cleaner $\mathrm{CO}_{2}$ environment is a luxury good. The evidence on the robustness of the squared affluence term is weak. Hence, at least within the sample, the relationship between $\mathrm{CO}_{2}$ emissions and real GDP per capita approximates a concave curve rather than an inverted U-shape. This conclusion supports many studies such as Shi (2003), York et al. (2003), Caviglia-Harris et al. (2009), Gassebner et al, (2011) and Martinez-Zarzoso and Maruotti (2011).

Energy intensity, the inverse of energy efficiency, exhibits significant coefficient estimates that fall within a narrow range in the final models from 0.4974 to 0.5367 . Both coefficients of economic structure are significantly positive. The coefficient for industry value added as a percent of GDP always exceeds the coefficient for services value added as a percent of GDP. While different sample countries and sample periods, static or dynamic models, as well as different estimators may lead to different estimation results, our estimated coefficients for energy intensity and economic structure fall close to those in Martinez-Zarzoso et al. (2007) and Martinez-Zarzoso and Maruotti (2011), where the authors use a dynamic model specification and the GMM estimator.

The effect of ESCOs on $\mathrm{CO}_{2}$ emissions is the focus of our study. The coefficient estimate is

\footnotetext{
7 The insignificant estimate in Model 7 also appears in Martinez-Zarzoso et al. (2007) and Martinez-Zarzoso and Maruotti (2011) when they use the difference GMM estimator for European countries and developing countries, respectively.
} 
negative and significant in all the models when we add the ESCO dummy variable as an explanatory variable, indicating ESCO activities around the world effectively reduce $\mathrm{CO}_{2}$ emissions. The estimates suggest that adoption of ESCO reduces $\mathrm{CO}_{2}$ emissions by around 5.0 percent in Model 8 (a 3.8 percent reduction in Model 11), assuming implicitly the effect is constant. The ESCO-CO $\mathrm{CO}_{2}$ relationship varies over time as evidenced by the interaction terms. Consider Model 9, for example. Adopting ESCO reduces $\mathrm{CO}_{2}$ emissions, on average, by 2.2 percent, ignoring the time effect. Each additional year since the adoption reduces $\mathrm{CO}_{2}$ emissions by 0.3 percent. According to the Vine's starting years in Table 1, the mean value of the number of years since ESCO adoption is 15 years. Thus, in our sample 15 years after adoption yields a reduction of $\mathrm{CO}_{2}$ emissions by 6.7 percent, on average. Model 10 considers potential non-linear effects (e.g., diminishing returns over time) through the interaction of the ESCO dummy variable and the squared value of the number of years since adoption. Now, the initial effect is 2.70 percent. Each additional year reduces $\mathrm{CO}_{2}$ emissions by 0.4 percent, but at a decreasing rate of 0.01 percent. After 15 years, the total reduction effect is 6.45 percent. This finding comes close to the effect identified above of a 6-percent reduction in $\mathrm{CO}_{2}$ emissions when we use only the ESCO dummy variable in Model 2.

The Kyoto Protocol receives criticism because the target reductions are too small to prevent global warming. In addition, the US has not ratified the Protocol. Recently, Grunewald and Martinez-Zarzoso (2009) and Iwata and Okada (2010) find a significantly negative effect of the commitments to the Kyoto Protocol on $\mathrm{CO}_{2}$ emissions. Almer and Winkler (2011) investigate whether committing to a specific GHG emissions target can affect the actual $\mathrm{CO}_{2}$ emissions of Australia, Canada, France, Germany, Great Britain, Italy, and Japan. They find no effect on actual emissions for the seven developed countries, except for Great Britain. We find negative coefficient 
estimate on the KYOTO dummy variable. The coefficient, however, proves sensitive to model settings with varying significance levels from insignificant to the 10-, 5-, to 1-percent levels. Model 8 suggests a reduction in $\mathrm{CO}_{2}$ emissions of around 1.4 percent. When we add the Kyoto Protocol dummy variable (KYOTO) as another predictor, no substantial change occurs in the ESCO estimates across the models. And the ESCO dummy variable always exhibits a much bigger effect than the KYOTO dummy variable on $\mathrm{CO}_{2}$ emissions.

In sum, the significant negative $E S C O$ effect on $\mathrm{CO}_{2}$ emissions is robust to the inclusion of a set of control variables, the different dates of the first ESCO, and the commitments to the Kyoto Protocol. Moreover, the ESCO effect improves over time.

\section{Conclusion}

This paper empirically investigates the effect of energy service companies (ESCOs) on $\mathrm{CO}_{2}$ emissions, using theoretically derived and modified dynamic IPAT model with a panel dataset of 129 countries over 1980 to 2007. The results indicate that ESCOs significantly reduce $\mathrm{CO}_{2}$ emissions. The magnitude of those decreases proves important, although not large relative to the effects of population, economic development, and energy use per unit of GDP. This finding supports the development of the ESCO industry worldwide as an instrument to reduce carbon dioxide emissions of energy use, particularly with regard to global warming.

We also find that ESCOs contribute more to the reduction in $\mathrm{CO}_{2}$ emissions than the Kyoto Protocol. Moreover, the effect of the ESCO on reducing $\mathrm{CO}_{2}$ emissions proves more stable and consistently significant than the Kyoto Protocol. Therefore, investment in the emerging energy-efficiency industry such as ESCOs proves more effective than the international agreement such as the Kyoto Protocol in reducing $\mathrm{CO}_{2}$ emissions.

The findings of this study not only contribute to the existing literature, but also deserve 
special attention from policy makers from both developed and developing countries. The international environmental policy developed in the Kyoto Protocol allows developed countries to bear most of the burden of cutting emissions, while developing countries remain relatively free to pollute. Global warming effects emerge irrespective of the country where emissions occur: one unit of pollutant equally contributes to the greenhouse effect wherever it is emitted. The issue of the earth's sustainability needs attention at all levels of development to achieve an effective solution to global environmental problems. All countries must formulate appropriate energy policies to promote energy efficiency and accelerate the switch to low carbon energy, decoupling environmental effects from economic growth. The newly emerging ESCO industry studied in this paper provides a good example.

The paper provides only preliminary results derived from two different surveys. ESCO development still remains in its early stages and must receive significant government support to succeed, as argued by Sarkar and Singh (2010). They list a series of barriers to energy-efficiency investments and state "To help remove implementation barriers to meet concrete energy-efficiency improvement targets on a global scale..., collective efforts of various institutions have to be mobilized and their convening force amongst the member countries needs to be utilized effectively to push the energy-efficiency acceleration agenda further.” (p.5569)

\section{Acknowledgements}

Financial support from the National Science and Technology Program-Energy (NSTPE), National Science Council, Taiwan, is gratefully acknowledged. 


\section{References:}

Almer, C., Winkler, R., 2011. Emissions targets and domestic actions: Dead end or last report? Available at: http://ssrn.com/abstract=1752282.

Asian Development Bank (ADB), 2009. Proposed loan and administration of grant republic of the Philippines: Philippine energy efficiency project.

Arellano, M., Bond, S., 1991. Some tests of specification for panel data: Monte Carlo evidence and an application to employment equations. Review of Economic Studies 58, 277-297.

Bertoldi, P, Rezessy, S, Vine, E., 2006. Energy service companies in European countries: Current status and a strategy to foster their development. Energy Policy 34, 1818-1832.

Bleyl, J. W., 2009. Competitive energy services (energy contracting, ESCO services). IEA DSM Task XVI, download available from www.ieadsm.org

Brock, W.A., Taylor, M. S., 2010. The green Solow model. Journal of Economic Growth 15, 127-153.

Carson, R. T., 2010. The environmental Kuznets curve: seeking empirical regularity and theoretical structure. Review of Environmental Economics and Policy 4, 3-23.

Caviglia-Harris, J. L., Chambers, D., Kahn, J. R., 2009. Taking the "U” out of Kuznets: A comprehensive analysis of the EKC and environmental degradation. Ecological Economics 68, 1149-1159.

Cole, M. A., Neumayer, E., 2004. Examining the impact of demographic factors on air pollution. Population and Environment 26, 5-21.

Cole, M. A., Rayner, A. J., Bates, J. M., 1997. The environmental Kuznets curve: An empirical analysis. Environment and Development Economics 2, 401-416.

Commoner, B., Corr, M., Stamler, P. J., 1971. The causes of pollution. Environment 13, 2-19.

Dasgupta, S., Laplante, B., Wang, H., Wheeler, D., 2002. Confronting the environmental Kuznets curve. Journal of Economic Perspectives 16, 147-168.

Davies, H. A., Chan, E., 2001. Experience of energy performance contracting in Hong Kong. Facilities 19, 261-268.

Dietz, T., Rosa, E. A., 1994. Rethinking the environmental impacts of population, affluence and technology. Human Ecology Review 1, 277-300.

Dietz, T., Rosa, E. A., 1997. Effects of population and affluence on $\mathrm{CO}_{2}$ emissions. Proceedings of the National Academy of Sciences (PNAS) 94, 175-179. 
Dinda, S., 2004. Environmental Kuznets curve hypothesis: A survey. Ecological Economics 49, 431-455.

Ehrlich, P. R., Holdren, J. P., 1971. Impact of population growth. Science 171, 1212-1217.

Ehrlich, P. R., Holdren, J. P., 1972. One-dimensional economy. Bulletin of the Atomic Scientists 16, 18-27.

Ellis, J., 2010. Energy service companies (ESCOs) in developing countries. International Institute for Sustainable Development, Manitoba, Canada.

Energy Sector Management Assistance Program (ESMAP), 2006. Financial energy efficiency: lessons from recent experience with a focus on Brazil, China and India. Washington, D. C.: International Bank for Reconstruction and Development / The Work Bank.

Gassebner, M., Lamla, M. J., Sturm, J., 2011. Determinants of pollution: What do we really know? Oxford Economic Papers 63,568-595.

Goldman, C, Hopper, N. C., Osborn, J., 2005. Review of US ESCO industry market trends: An empirical analysis of project data. Energy Policy 33, 387-405.

Grossman, G., Krueger, A., 1995. Economic growth and the environment. Quarterly Journal of Economics 110, 353-377.

Grunewald, N., Martines-Zarzoso, I., 2009. Driving factors of carbon dioxide emissions and the impact from Kyoto Protocol. CESifo working paper No. 2758.

Holtz-Eakin, D., Selden, T. M., 1995. Stoking the fires? $\mathrm{CO}_{2}$ emissions and economic growth. Journal of Public Economics 57, 85-101.

International Panel on Climate Change (IPCC), 2007. Climate change 2007: Synthesis report. New York, NY: United Nations, International Panel on Climate Change.

Iwata, H., Okada, K., 2010. Greenhouse gas emissions and the role of the Kyoto Protocol. MPRA Paper No. 22299.

Kijima, M., Nishide, K., Ohyama, A., 2010. Economic models for the environmental Kuznets curve: A survey. Journal of Economic Dynamics \& Control 34, 1187-1201.

Kiss, B., Bertoldi, P., Razessy, S., 2007. Latest developments of the ESCO industry across Europe. ECEEE 2007 Summer Study, Saving Energy - Just Do it, 333-344.

Lee, C., Chiu, Y., Sun, C., 2009. Does one size fit all? A reexamination of the environmental Kuznets curve using the dynamic panel data approach. Review of Agricultural Economics 31, 751-778. 
Lee, M. K., Park, H., Noh, J., Painuly, J. P., 2003. Promoting energy efficiency financing and ESCOs in developing countries: Experiences from Korean ESCO business. Journal of Cleaner Production 11, 651-657.

Limaye, D. R., Limaye, E. S., 2009. Scaling up energy efficiency: the case for a super ESCO. SRC Research Paper 2009-03.

Linares, P., Labandeira, X., 2010. Energy efficiency: Economics and policy. Journal of Economic Surveys 24, 573-592.

Linares, P., Perez-Arriaga I., 2009. Promoting investment in low-carbon energy technologies. European Review of Energy Markets 3, 1-23.

Martinez-Zarzoso, I., Bengochea-Morancho, A., Morales-Lage, R., 2007. The impact of population on $\mathrm{CO}_{2}$ emissions: Evidence from European countries. Environmental and Resource Economics 38, 497-512.

Martinez-Zarzoso, I., Maruotti, A., 2011. The impact of urbanization on $\mathrm{CO}_{2}$ emissions: Evidence from developing countries. Ecological Economics 70, 1344-1353.

Okay, N., Akman, U., 2010. Analysis of ESCO activities using country indicators. Renewable and Sustainable Energy Reviews 14, 2760-2771.

Okay, E., Okay, N., Konukman, A. E. S., Akman, U., 2008. Views on Turkey’s impending ESCO market: is it promising? Energy Policy 36, 1821-1825.

Patlitzianas, K. D., Doukas, H., Psarras, J., 2006. Designing an appropriate ESCOs’ environment in the Mediterranean. Management of Environmental Quality: An International Journal 17, 538-554.

Patlitzianas, K. D., Psarras, J., 2007. Formulating a modern energy companies' environment in the EU accession member states through a decision support methodology. Energy Policy 35, 2231-2238.

Popp, D., 2004. "ENTICE”: Endogenous technological change in the DICE model of global warming. Journal of Environmental Economics and Management 48, 742-768.

Popp, D., 2010. Innovation and climate policy. National Bureau of Economic Research Working Paper 15673.

Poumanyvong, P., Kaneko, S., 2010. Does urbanization lead to less energy use and lower $\mathrm{CO}_{2}$ emissions? A cross-country analysis. Ecological Economics 70, 434-444.

Raupach, M. R., Marland, G., Ciais, P., Quere, C. L., Canadell, J. G., Klepper, G., 2007. Global and regional drivers of accelerating $\mathrm{CO}_{2}$ emissions. Proceedings of the National Academy of Sciences (PNAS) 104, 10288-10293. 
Roodman, D., 2009. How to do xtabond2: An introduction to difference and system GMM in Stata. The Stata Journal 9, 86-136.

Sarkar, A., Singh, J., 2010. Financing energy efficiency in developing countries -- lessons learned and remaining challenges, Energy Policy 38, 5560-5571.

Satchwell, A., Goldman, C., Larsen, P., Gilligan, D., Singer, T., 2010. A survey of the U.S. ESCO industry: Market growth and development from 2008 to 2011. Lawrence Berkeley National Laboratory: LBNL-3479E, Berkeley, CA, June.

Shi, A., 2003. The impact of population pressure on global carbon dioxide emissions, 1975-1996: Evidence from pooled cross-country data. Ecological Economics 44, 29-42.

Shito, E., 2003. Japan's energy-saving policy and first ESCO project on private fund undertaken by local government. ECEEE 2003 Summer Study - Time to Turn Down Energy Demand, 881-884.

Singh, J., Limaye, D., Henderson, B., Shi, X., 2009. Public procurement of energy efficiency services: lessons from international experience, The World Bank.

Stern, D. I., 2004. The rise and fall of the environmental Kuznets curve. World Development 32, 1419-1439.

Taylor, R. P., Govindarajalu, C., Levin, J., Meyer, A. S., Ward, W. A., 2008. Financing energy efficiency: Lessons from Brazil, China, India and beyond. Washington D. C.: The World Bank.

United States Agency for International Development (USAID), 2010. Development of a Super ESCO to implement a 600 MV energy efficiency power plant: Preliminary business strategy and implementation plan.

Urge-Vorsatz, D., Koppel, S., Liang, C., Kiss, B., Nair, G. G., Celikyilmaz, G., 2007. An assessment of energy service companies (ESCOs) worldwide. London: World Energy Council.

Vine, E., 2005. An international survey of the energy service company (ESCO) industry. Energy Policy 33, 691-704.

Vine, E. L, Murakoshi, C., Nakagami, H., 1998. International ESCO business opportunities and challenges: A Japanese case study. Energy 23, 439-447.

Waggoner, P. E., Ausubel, J. H., 2002. A framework for sustainability science: a renovated IPAT identity. Proceedings of the National Academy of Sciences (PNAS) 99, 7860-7865.

World Energy Council (WEC) 2008. Energy efficiency policies around the world: Review and evaluation. London: World Energy Council Publications. 
Yamaji, K., Matsuhashi, R., Nagata, Y., Kaya, Y., 1991. An integrated system for $\mathrm{CO}_{2} / \mathrm{energy}^{\mathrm{GNP}}$ analysis: case studies on economic measures for $\mathrm{CO}_{2}$ reduction in Japan. Workshop on $\mathrm{CO}_{2}$ Reduction and Removal: Measures for the Next Century, March 19, International Institute for Applied System Analysis, Laxenburg, Austria.

York, R., Rosa, E. A., Dietz, T., 2003. STIRPAT, IPAT and ImPACT: analytic tools for unpacking the driving forces of environmental impacts. Ecological Economics 46, 351-365. 
Table 1: $\quad E S C O$ and the Kyoto Protocol countries and starting years

\begin{tabular}{|c|c|c|c|}
\hline Country & Vine's $^{\mathrm{a}}$ & Kiss's $^{b}$ & the Kyoto Protocol ${ }^{\mathrm{d}}$ \\
\hline Argentina & 1995 & & \\
\hline Australia & 1990 & & 2007 \\
\hline Austria & 1995 & 1998 & 2002 \\
\hline Belarus & & & 2005 \\
\hline Belgium & 1990 & 1990 & 2002 \\
\hline Brazil & 1992 & & \\
\hline Bulgaria & 1995 & 1995 & 2002 \\
\hline Canada & 1982 & & 2002 \\
\hline Chile & 1996 & & \\
\hline China & 1995 & & \\
\hline Columbia & 1997 & & \\
\hline Côte d'Ivoire & 2000 & & \\
\hline Croatia & & 2003 & 2007 \\
\hline Czech Republic & 1993 & 1993 & 2001 \\
\hline Denmark & & & 2002 \\
\hline Egypt & 1996 & & \\
\hline Estonia & 1986 & 1986 & 2002 \\
\hline Finland & 2000 & 2000 & 2002 \\
\hline France & & 1993 & 2002 \\
\hline Germany & 1993 & 1993 & 2002 \\
\hline Greece & & & 2002 \\
\hline Ghana & 1996 & & \\
\hline Hungary & 1990 & 1991 & 2002 \\
\hline Iceland & & & 2002 \\
\hline India & 1994 & & \\
\hline Ireland & & 2006 & 2002 \\
\hline Italy & 1983 & 1983 & 2002 \\
\hline Japan & 1997 & & 2002 \\
\hline Jordan & 1994 & & \\
\hline Kenya & 1997 & & \\
\hline Korea & 1992 & & \\
\hline Latvia & & 2001 & 2002 \\
\hline Liechtenstein & & & 2004 \\
\hline Lithuania & 1998 & 1998 & 2003 \\
\hline Luxembourg & & & 2002 \\
\hline Mexico & 1998 & & \\
\hline Monaco & & & 2006 \\
\hline Morocco & 1990 & & \\
\hline Nepal & 2002 & & \\
\hline Netherlands & & 2000 & 2002 \\
\hline New Zealand & & & 2002 \\
\hline Norway & & & 2002 \\
\hline Philippines & 1995 & & \\
\hline Poland & 1995 & 1995 & 2002 \\
\hline Portugal & & & 2002 \\
\hline Romania & & & 2001 \\
\hline Russian Federation & & & 2004 \\
\hline Slovak Republic & 1995 & 1994 & 2002 \\
\hline Slovenia & & 2001 & 2002 \\
\hline South Africa & 1998 & & \\
\hline Spain & & 1987 & 2002 \\
\hline Sweden & 1978 & 1978 & 2002 \\
\hline Switzerland & 1995 & & 2003 \\
\hline Thailand & 2000 & & \\
\hline Tunisia & 2000 & & \\
\hline Turkey & & & 2009 \\
\hline Ukraine & 1996 & & 2004 \\
\hline United Kingdom & 1980 & 1984 & 2002 \\
\hline United States $^{\mathrm{c}}$ & 1975 & 1975 & \\
\hline
\end{tabular}


Table 2: Description of the Variables

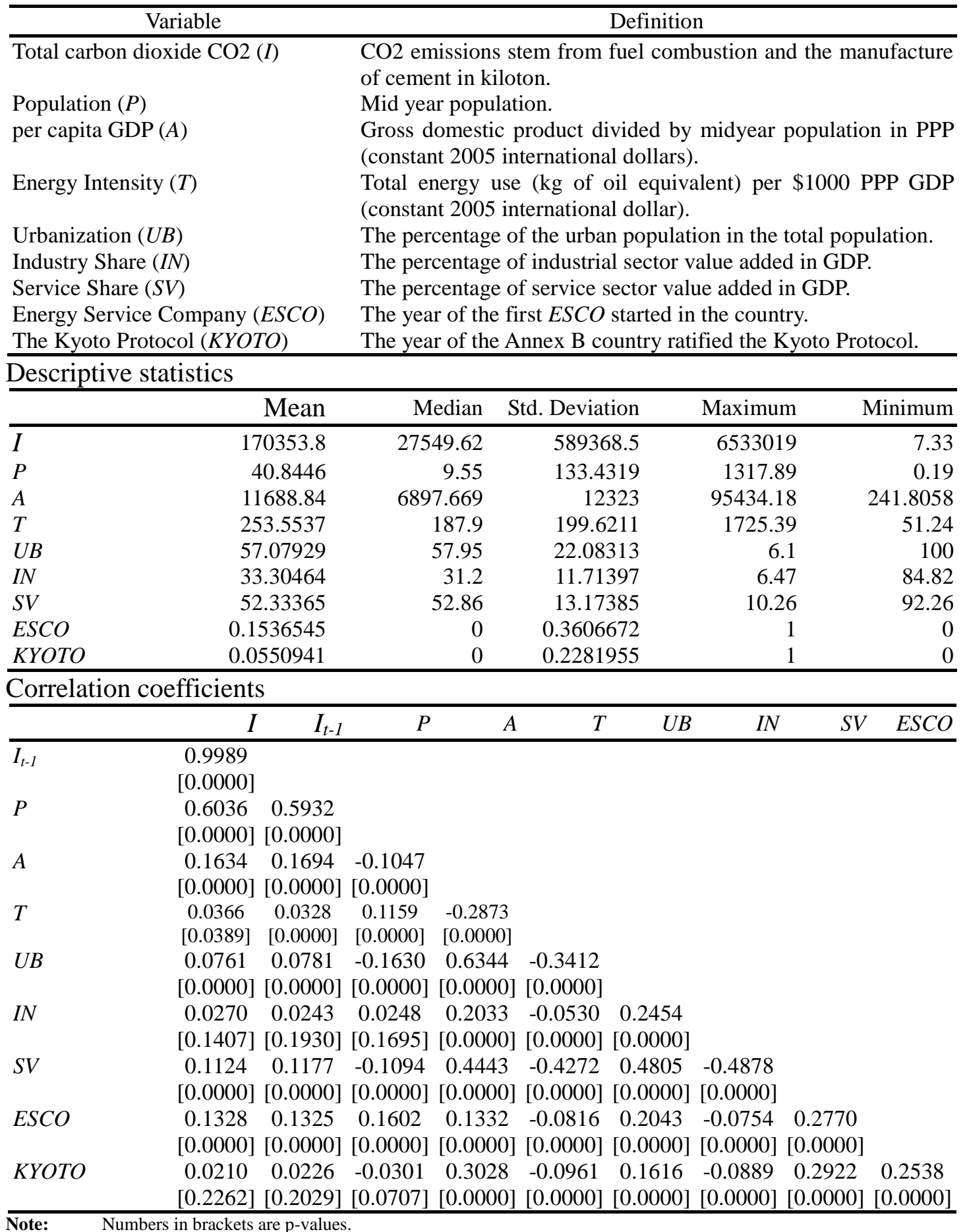


Table 3: Estimation results, 1980-2007

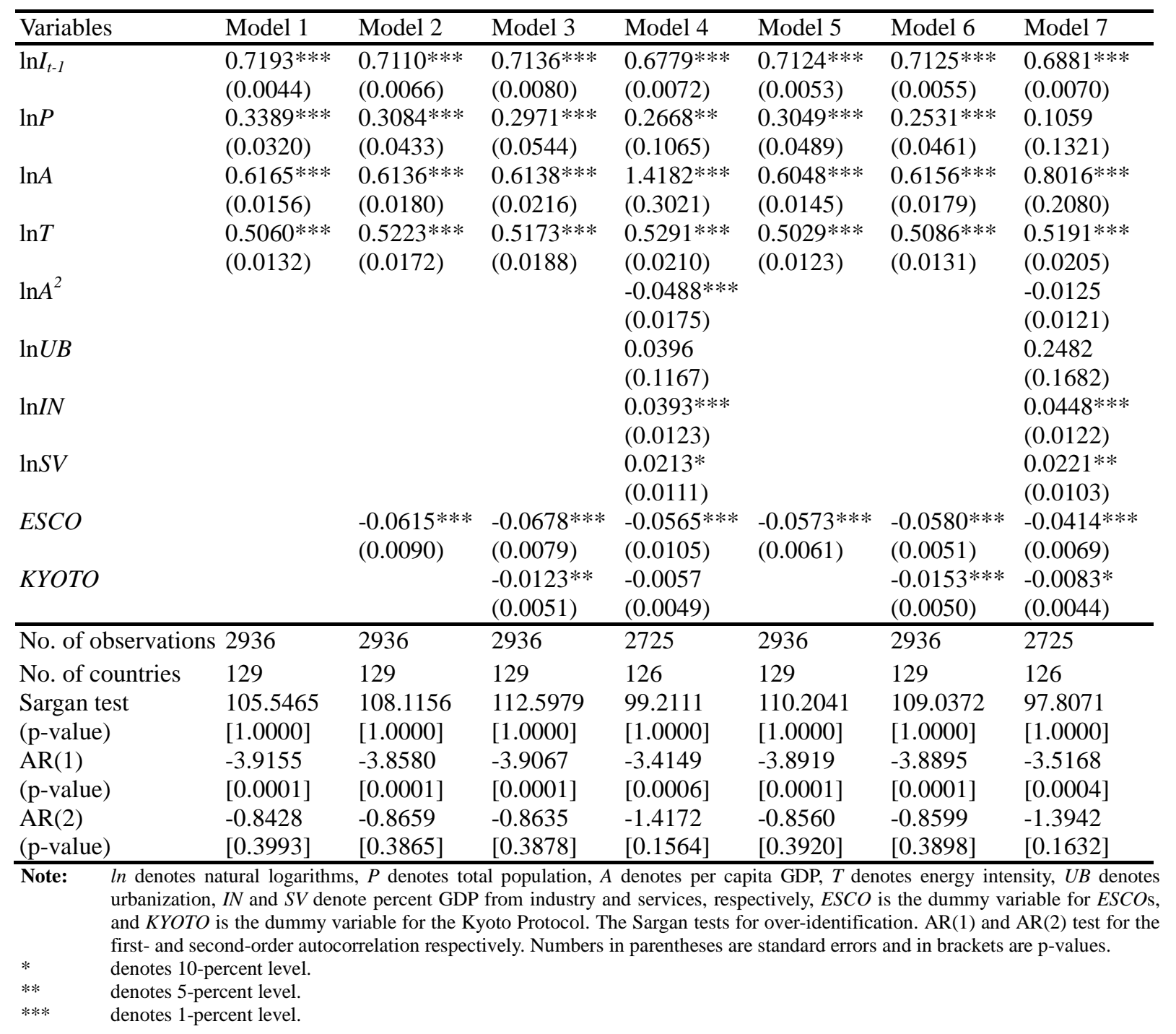


Table 4: Final Models, 1980-2007

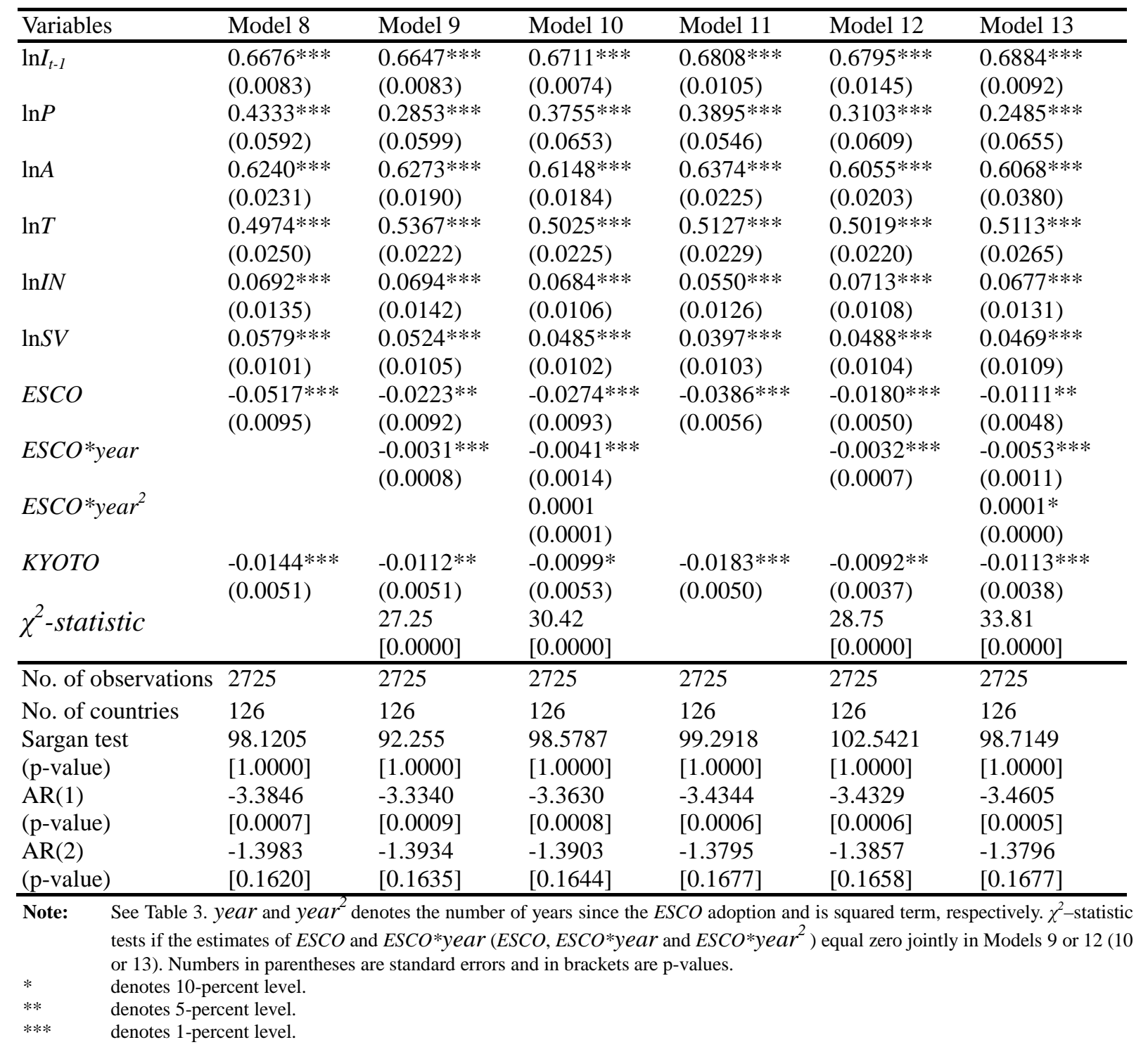

